\title{
Decolonising ideas of healing in medical education
}

\author{
Lokugamage A.U, Ahillan T, Pathberiya S.D.C
}

\section{Abstract}

The legacy of colonial rule has permeated into all aspects of life and contributed to healthcare inequity. In response to the increased interest in social justice, medical educators are thinking of ways to decolonise education and produce doctors who can meet the complex needs of diverse populations. This paper aims to explore decolonising ideas of healing within medical education following recent events including the University College London Medical School's Decolonising the Medical Curriculum public engagement event, the Wellcome Collection's Ayurvedic Man: Encounters with Indian Medicine exhibition, and its symposium on Decolonising Health, SOAS University of London's Applying a Decolonial Lens to Research Structures, Norms and Practices in Higher Education Institutions and University College London Anthropology Department's Flourishing Diversity Series. We investigate implications of 're-centring' displaced indigenous healing systems, medical pluralism and highlight the concept of cultural humility in medical training, which while challenging, may benefit patients. From a global health perspective, climate change debates and associated civil protests around the issues resonate with indigenous ideas of planetary health, which focus on the harmonious interconnection of the planet, the environment and human beings. Finally, we look further at its implications in clinical practice, addressing the background of inequality in healthcare amongst the BAME (Black, Asian and minority ethnic) populations, intersectionality, and an increasing recognition of the role of inter-generational trauma originating from the legacy of slavery. By analysing these theories and conversations that challenge the biomedical view of health, we conclude that encouraging healthcare educators and professionals to adopt a 'decolonising attitude' can address the complex power imbalances in health and further improve person-centred care.

\section{Introduction}

In recent years, a movement, led by humanities undergraduates, to 'decolonise' the traditional university curriculum, has gathered momentum. Its aims are to provide a more inclusive education, one that looks beyond the traditional Eurocentric white male syllabus to include more women and black and minority ethnic authors.

Decolonising the curriculum is an emerging issue for all types of higher educational curricula as seen in the University College London (UCL) initiative entitled 'Why is my curriculum white'[1]; Priyamvada Gopal's (University of Cambridge) provocative article in the Guardian newspaper, 'Yes, we must decolonise: our teaching has to go beyond elite white men'[2], and SOAS, University of London blog 'Decolonising the curriculum: what's all the fuss about?'.[3]

Efforts by the humanities departments for inclusivity finds its parallels in medicine's discussions on how a more inclusive curriculum can improve disease diagnosis and treatment, patient management, professionalism and quality of care. Stone et al speaking from a planetary health education curriculum perspective also say:

"Understanding the differences between equality and equity in theory and practice, and concepts of marginalisation, vulnerability, resilience, and who benefits and is harmed in a given scenario, is a core objective of planetary health teaching. Since the effects of environmental change on human health are heterogeneous and mediated by factors such 
as geographical scale, temporal scale, socioeconomic factors, and political and cultural context, students should think critically about whose health is at stake and how it is measured."[4]

As a result, more recently, medical educators are beginning to think of how this process of decolonisation can apply to medical education. Medical schools must address the equality and diversity agenda, which requires that the education system produce doctors who can meet the complex needs of a diverse population. Marginalised groups have poorer healthcare outcomes than patients at the top of the post-colonial hierarchy, such as patients who are white, male, high social class and heterosexual.

This paper examines this professional and legal impetus to decolonise the medical curriculum and how elements of decolonisation can be applied to the modern medical curriculum.

\section{The colonial backdrop of dehumanised care}

Decolonising the history of medicine promotes awareness and questions the traditional narratives and power imbalances in order to disrupt the legacy of white male patriarchal colonisation of medicine. By reassessing past medical colonial legacies, it could be possible to re-frame, reorient and reform the profession. Porter, a cultural historian, says that the $18^{\text {th }}$ Century European Enlightenment and subsequent professionalism of medical practice encouraged the school of scientific enquiry which privileged experimentation and discovery at the expense of empathy.[5] It encouraged the practitioners to perceive the patient as a subject first and a human second. Over the course of centuries this emboldened the European male practitioners and moulded a patriarchal medical system, allowing a state of medical cultural arrogance to grow. The benefits of the $18^{\text {th }}$ Century Enlightenment were to favour reason over superstition and further scientific advancement. However, in the process of establishing medical criteria, it entrenched power hierarchies, excluded other ideas of healing, and other types of practitioners such a midwives, folk healers or indigenous healing systems in the colonies. Medical pluralism was squeezed out of the growing medical power hierarchy.

Proponents of medical decolonisation argue that the story of Dr. Marion Sims (who has been named as the 'father of gynaecology' due to his development of the Sims speculum and surgical techniques for the repair of vesico-vaginal fistulae) which is omitted currently, should be included in medical curricula. Sims's motivation was to repair fistulae in black women slaves, so they could return to the workforce rather than to heal them - representing the $18^{\text {th }}$ century enlightenment's aspect of dehumanisation. The fistulas in this population were a result of acquiring the skills of forceps delivery by obstetricians whilst disregarding and ignoring indigenous practices of midwifery. The black women slaves that were experimented on to improve surgical technique did not give their consent to the procedure and nor were they given any sort of analgesia. The names of three of these women, Anarcha, Betsy and Lucy, have now found equal fame from a human rights perspective. After protests regarding their treatment, Sims' statue in Central Park, New York, USA, has been relocated.[6]

Likewise, in the history of the Tuskegee syphilis experiments in the USA[7], where 600 black men were recruited to eugenics experiments to follow the natural history of untreated syphilis. They were intentionally denied treatment though a lack of honesty. The US government has since apologised, and compensated the families. Proponents of decolonisation argue that this story should have a place within ethics and law syllabi of medical schools. 
'UNCONSCIOUS BIAS refers to a bias that we are unaware of, and which happens outside of our control. It is a bias that happens automatically and is triggered by our brain making quick judgments and assessments of people and situations, influenced by our background, cultural environment and personal experiences.' [8]

'CULTURAL COMPETENCE education for health professionals aims to ensure all people receive equitable, effective healthcare, particularly those from culturally and linguistically diverse backgrounds.'[9]

'CULTURAL HUMILITY was used in a variety of contexts from individuals having ethnic and racial differences, to differences in sexual preference, social status, interprofessional roles, to healthcare provider/patient relationships. The attributes were openness, self-awareness, egoless, supportive interactions, and self-reflection and critique. The antecedents were diversity and power imbalance. The consequences were mutual empowerment, partnerships, respect, optimal care, and lifelong learning. Cultural humility was described as a lifelong process. With a firm understanding of the term, individuals and communities will be better equipped to understand and accomplish an inclusive environment with mutual benefit and optimal care.'[10]

The process of dissipating cultural arrogance in favour of cultural humility (Figure 1) as part of decolonisation would entail disrupting elements of the hidden medical curriculum where the legacy of colonial norms operates as unconscious bias in professional behaviours. By directly tackling the history of medicine through the lens of decolonisation within the ethics and law, anthropology or global health frameworks of the syllabus, medical educators can critically evaluate the evolution of patient centred care, and reflect on who, why and how the profession chooses to commemorate knowledge. Equally educators can then contextualise the legal advancements of human rights in healthcare.

\section{Professional and legal impetus to decolonise the medical curriculum Professional impetus}

The case for decolonising the medical curriculum stems from a social justice perspective on the persistent legacy of colonialism which results in power imbalances and healthcare inequity.[11] Decolonising the curriculum could equip future doctors with the professional literacy and confidence to deal with the complexity and uncertainty of growing 'grass-roots' decoloniality activism by the patients, academics and public. This debate has started difficult conversations which we will explain further in this article. 'White Fragility' is the refutation of the existence of structural racism as described in Robin DiAngelo's bestselling book 'White Fragility: Why It's So Hard for White People to Talk About Racism'[12]. Defensive responses regarding the concept of decolonisation, from doctors who have a socio-cultural background which we could call 'white coat privilege could be regarded as demonstrations of 'privilege fragility' a term that we have coined for this article. Privilege fragility is at odds with the embodiment of the diversity and equality agenda within professional behaviours, such as displaying 'cultural humility' (Figure 1) for the purposes of neutralising power imbalances in education and healthcare. 
Susan Goldsmith, Chief Operating Officer and Deputy Chief Executive of the General Medical Council (GMC) said:

\begin{abstract}
"We understand and value the diversity within the medical profession and recognise the importance of supporting doctors to serve a diverse population across the UK ... we have to be compliant with equality and human rights legislation, but being fair goes way beyond just meeting legal requirements. It is an integral part of everything that we do."[13]
\end{abstract}

These ideas are further re-enforced in the GMC's Outcomes for Graduates 2018 report. [14]

\title{
Legal impetus
}

The legal incentives for promoting decolonisation of the medical curriculum are inextricably tied up with the risks of litigation and the relevant laws in statute, case law, as well as international legal instruments.

The European Convention on Human Rights[15] has a number of provisions which protect an individual's rights in a healthcare setting. In particular Articles 2, 3, 8, 12 and 14 enable patients to "make choices in line with their own opinions and values - even if those choices seem irrational, illadvised or rash to others."[16] However, in addition to the above Convention rights, the Article 9 right to freedom of thought, conscience and religion, is also pertinent because some modalities of treatment, from the perspective of the patient, may also have a significant spiritual/religious component. Examples of these include the many international cases relating to Jehovah's Witnesses refusing blood transfusions[17]. It follows that restricting indigenous modalities of treatments, which have religious/spiritual elements, may also breach the patient's Article 9 rights.

In Montgomery $v$ Lanarkshire Health Board [2015] the supreme court said that a patient's decision on whether or not to incur a risk regarding their care "does not depend exclusively on medical considerations" and the "patient is entitled to take into account her own values, her own assessment of the comparative merits." Further the "relative importance attached by patients to quality as against length of life, or to physical appearance or bodily integrity as against the relief of pain, will vary from one patient to another." This is because many reasons "may affect their attitude towards a proposed form of treatment and the reasonable alternatives. The doctor cannot form an objective, 'medical' view of these matters, and is therefore not in a position to take the 'right' decision as a matter of clinical judgment."[18] A possible explanation for the doctors not being able to attach a similar level of significance as patients do to issues of relevance to them, may be because such a decision does not fit with doctors' paradigm of medicine or health.[19]

If doctors are unable to act in a person-centred manner, which, in diverse populations would entail being culturally competent by exercising cultural humility (Figure 1), it may leave their actions falling short of required standard of duty of care and therefore open to litigation. Therefore as Lord Kerr and Lord Reed in the Supreme Court put it, it is "necessary to impose legal obligations, so that even those doctors who have less skill or inclination for communication, or who are more hurried, are obliged to pause and engage in the discussion which the law requires."[18] Furthermore, Outcomes for Graduates 2018 specifies that graduates "must demonstrate knowledge of the principles of the legal framework" as well as "the importance of the links between pathophysiological, psychological, spiritual, religious, social and cultural factors for each individual."[14] 


\section{Decolonisation and medical education}

\section{Recent decolonial public engagement events}

\section{University College London (UCL) Medical School}

In effort to improve curricula delivery, the UCL Medical School Clinical and Professional Practice team held two public engagement events. The first event, 'Practically Creating an Inclusive Curriculum', 2017[20], received feedback that there should be an exploration of how to decolonise the medical curriculum. This in turn inspired a second public engagement event in 2018 named 'Decolonising the Medical Curriculum'[21] which focused on: decolonising the body; decolonising the curriculum; decolonising learner experience; decolonising educational space; decolonising professional behaviours; and decolonising ideas of healing. The event broadly covered the areas of: identifying symptoms and signs in varying skin tones in the context of over diagnosis/underdiagnosis; feminist pedagogy describing sessions using patient narratives e.g. session on violence against women; mapping the diversity curriculum; the attainment gap and students experience of racism; the UCL eugenics enquiry; anthropology as a vehicle of improving professional behaviours; biomedicine's colonisation of indigenous healing systems.[21]

\section{Wellcome Collection}

The 'Ayurvedic Man: Encounters with Indian Medicine' accompanied an associated 'Decolonising Health symposium' at the Wellcome Collection, in 2018.[22] The exhibition explored Ayurvedic medicine in South Asia through its museum antiquities collection. The exhibition asked how medicine has been transformed by biomedical and cultural exchanges and what the impact of colonialism has been on medical heritage. As the Wellcome says:

"we are at a time of growing popularity of pluralistic approaches to health, societies around the world are at increasing risk of losing natural resources, medicinal plants and traditional knowledge. Ayurvedic Man highlighted the delicate balance between sharing and protecting heritage, cultural resources and environmental biodiversity"[23].

\section{UCL Anthropology Department - Flourishing Diversity}

The 'Flourishing Diversity Series'[24] were a series of high-profile events in September 2019 which promoted actively listening to the voices, stories and wisdom of the representatives from remote indigenous communities around the world gathered in London. These listening encounters promoted key themes about sustainability, climate change, indigenous land rights, indigenous ideas of healing, and collective sharing of indigenous knowledge. The messages from these public engagement events attracted the attention of major news outlets such as the BBC World Service[25] and TIME magazine[26].

\section{SOAS University of London}

The 2019 'Applying a Decolonial Lens to Research Structures, Norms and Practices in Higher Education Institutions'[27] event considered how global research has been influenced by colonial legacies which affect the very knowledge we impart in medical education. Attention was drawn to geographic biases in research outputs whereby the institutions of the global north dominate the evolution of global knowledge. Conversations explored how funders could mitigate these geographical biases through active partnership with research bodies of the nations of the global south and also active listening to the voices of indigenous people. 


\section{Learning from active listening to decolonise medical education}

Following the active listening of the above events, we have distilled concepts that may have been omitted from conventional top-down organisational equality and diversity policy in the context of medical education. These concepts may feel uncomfortable, however, the emerging 'grass-roots' interest in decolonisation is a liminal space for educational transformation. In this article, we have further explored areas specific to the concept of healing in the individual and in the population.

Figure 2. One man in traditional religious clothing. Credit: Wellcome Collection[28].

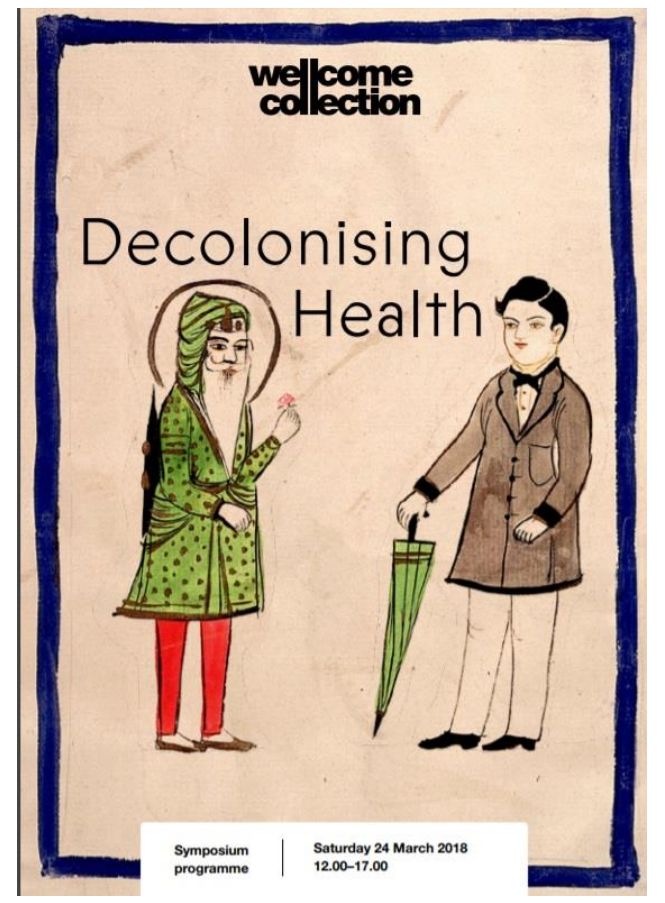

\section{Medical Pluralism}

\section{The tension between western and traditional healing systems}

The image (Figure 2) used to publicise the Wellcome[23] exhibition and associated symposium, of two men meeting - one in western dress and the other in traditional Indian attire with a halo around his head - stimulated some thoughts on definitions of the term 'enlightenment' and its different meanings in Western and Eastern contexts. In the East (India, Sri Lanka, China etc), traditional healing ideology about overcoming illness through indigenous medicine (e.g. Ayurveda, Traditional Chinese Medicine etc) can be viewed, on a superficial level, as symptom relief/cure, but their philosophies have a deeper endpoint of paving the road to 'enlightenment' of mind, body, and spirit, through attempting to create ecological balance by working with nature.

In the West, the ' $18^{\text {th }}$-century Enlightenment' refers to the overturning of superstition with science and logic; in European colonies this contributed to the subjugation of indigenous medicine in favour of Western health practices. This meant that Eastern practices, such as Ayurveda, Traditional Chinese Medicine and other indigenous healing systems, were regarded through the sceptical lens of a Western medical perspective, and their efficacy rejected. The exertion of colonialism led to Europeans establishing their own biological, structural and cultural superiority and their own epistemology on the narratives of healing as the only legitimate knowledge base of medicine in the countries they colonised.[29] However, the unique context of decolonisation of healing practices means that the process depends not only on dismantling colonial epistemologies 
and aspects of patriarchal institutions, but also on simultaneously re-centring the displaced indigeneity.

Eastern ideas of healing, as with many other indigenous healing systems, encompass a range of multiple outcomes of mind, body and spirit on receiving nuanced individualised treatments. Such outcomes are awkward to capture with standard epidemiological mathematics and 'one-size-fitsall' study design (which prefer to look at one primary endpoint). Hence it is challenging to develop an evidence base according to Western criteria. However, as conversations relating to decolonisation in healthcare circulate and contribute to ongoing health activism, it will be interesting to see what will unfold and what patients want from healthcare systems.

The decolonising agenda to 're-centre' displaced indigenous healing systems will be challenging for those in biomedicine due to the paucity of epidemiological evidence. However, equality and diversity training in professionalism within education, could have an anthropological component that includes the concept of 'cultural humility' (Figure 1), where, in this case, there could be awareness that Western medical practice is just one of many global healing systems. This could throw light on biomedical unconscious bias. However, it should be noted that the Outcomes for Graduates 2018 says that:

graduates should "respect patient choices about the use of complementary therapies, and have a working knowledge of the existence and range of these therapies, why patients use them, and how this might affect the safety of other types of treatment that patients receive".[14]

Often the unconscious bias is based on the narrative of the assumed superiority of Western medicine based on evidence-based research. However, reviews of the evidence base of medicine guidelines, such as Wright et al, say that "Practice guidelines by specialist societies are surprisingly deficient" and indicate that only a minority of medical guidelines are based on grade A evidence and the majority of medicine practice is not based on evidence (shaped as best practice) or lesser grades of evidence.[30], [31] Analyses of evidence levels in obstetrics and gynaecology and have found patterns of predominantly low grades of evidence for the Royal College of Obstetricians and Gynaecologists guidelines[32] and the Society of Obstetricians and Gynaecologists of Canada guidelines[33]. Subsequently, it could be postulated that biomedicine may be more belief based than generally presumed as explored in Charles et al's paper 'The evidence-based medicine model of clinical practice: scientific teaching or belief-based preaching?'.[34]

Given that both western and indigenous healing systems have deficits of high-quality scientific evidence, there could be a case for looking beyond the western $v s$. traditional antagonism, in order to explore opportunities for synergy and co-delivery in a medical pluralistic, person-centred approaches to healthcare.

\section{Transgenerational trauma and indigenous ideas of healing}

Demographic studies show ethnic differences in diagnosis of psychiatric disease.[35] However, attention needs to be paid to research into inter-generational trauma originating from the legacy of slavery and subjugation of an indigenous way of life.[36] Decoloniality academics have proposed that those affected should be approached by being both respectful of the indigenous system of beliefs and healing systems of their ancestors as well as making available standard psychological therapies. Publications in humanities such as Fay's in 'Decolonising mental health one prejudice at a time: psychological, sociological, ecological and cultural considerations'[37], Davis's PhD thesis[38], Quijano's 'Coloniality and Modernity/Rationality'[29] and Linklaters' 'Decolonizing 
Trauma Work: Indigenous Stories and Strategies'[39] have highlighted the inadequacies of current psychological and psychiatric practices in dealing with this reported phenomena.

The Office of Hawaiian Affairs is presently backing a Bill promoting native Hawaiian concepts of well-being, culturally-grounded health methodologies and traditional healing and health practices.[40] This was a governmental response to findings that colonised style of western healthcare did not meet the mental health needs of indigenous people in Hawaii. The whitepaper to the Bill says that the "health programs and services that are aligned with Native Hawaiian cultural identity, values and beliefs can significantly increase the number of Native Hawaiians who utilize mental health services."[41]

An underlying factor relevant may be the stigma attached to psychiatric disorders which are seen differently from an indigenous treatment perspective. For instance, psychiatric conditions are commonly seen in indigenous communities as an invasion of an external entity which can be remedied in rituals or looking at psychiatric conditions as a symptom of disharmony in the community as opposed to the individual. Another perspective might be that psychological conditions are a result of westernisation and labelling of conditions. It is probably due to the above reasons that the Diagnostic and Statistical Manual of Mental Disorders (DSM-5) incorporates a greater cultural sensitivity in its latest update. See also Youngs and Nadeau's article on Decolonising the Body: Restoring Sacred Vitality which describes their experience in setting up a program in Canada to help native women who have suffered sexual, racist and colonial violence, makes an interesting contribution in this area.[42]

Molecular medicine has also started to accrue epigenetic evidence[43] that suggest the transgenerational transmission of DNA methylation changes from parents to children derived from the experience of trauma. It follows that there could be cross linkage between biomedicine and humanities and to act synergistically to explore new conversations on inter-generational trauma and its treatment. Furthermore, we introduce these ideas into this paper within the context of decolonising medical education and propose inclusion of this aspect of cultural psychiatry within the intersect between the Mental Health and Social Determinants of Health syllabus.

An ideal educational vehicle for creating professional awareness and cultural sensitivity around indigenous systems of healing would be for all medical students to have a basic knowledge of medical anthropology. For instance, the UCL Medical School curriculum gives students the opportunity to take a special study component which is an anthropological project looking at mental health from an indigenous perspective in a 'Culture, ethics, and religion in the clinical encounter' mini course. The course explores some of the complexities of clinical practice with culturally diverse patients for a selection of students. Medical schools in general could develop medical anthropology as part of the core curriculum, as a way of decolonising the medical curriculum and improving cultural competence and a cultural humility in professional behaviours (Figure 1). This viewpoint was expressed by a student participant in the Decolonising the Medical Curriculum event in terms of culture in the clinical encounter and her essay and talk can be viewed at the project's website.[44]

\section{Elements of a modern medical curriculum}

It is invariably difficult to define the areas that should be included in regard to decolonisation within the medical curriculum. However, in addition to the areas discussed above, the following areas have been highlighted as important by the public who attended the prior mentioned decolonising public engagement events. Due the nature of public engagement events, the public's 
contribution identified through active listing to the public's voice, does not at times emerge in a logical and structured way.

\section{Decolonising global health and research}

At the Wellcome Decolonising Health symposium[22], Branwyn Poleykett, anthropologist and postdoctoral research associate in the Centre for Research in the Arts, Social Sciences and Humanities, University of Cambridge pointed out that decoloniality is rising as a challenge to the average biomedical view of global health and biomedical research funding. She referred to Richard Smith (who was the editor of the BMJ until 2004) who said in his BMJ blog that there was a popular way of talking about developments in global health circles at the moment, which said that the global health '3.0' model is being currently upgraded to the more modern global health '4.0' model[45]. But Poleykett, reasoned that there are decolonising arguments that say that if we are to use a 'computer upgrade' type terminology for global health development, then it should be acknowledged that global health '1.0' was colonialism (an epoch of discrimination) and that global health '2.0' was post-colonial international health. The global health '2.0' model had contained many unresolved aspects of discrimination, inequality and power imbalances between former colonising nations and those colonised. From her anthropological viewpoint, the legacy of models ' $1.0^{\prime}$ ' and '2.0' are still eroding and undermining the ideologies of the global health ' $3.0^{\prime}$ ' and the aspirations of version ' 4.0 '. Thus, Global Health ' 4.0 ' is still riddled with the legacy of colonisation and not a completely virtuous crusade for health improvement. Hence this complexity needs to be incorporated from a decoloniality perspective into medical syllabus of global health education. Poleykett's arguments at this event were relevant as the Wellcome Trust is a large funder of global health research and the Wellcome Collection is a large repository of colonial antiquities related to health and medicine.

Also circling back to the arguments of global health and the power imbalances of the able and disabled, Meekosha's article on 'Decolonising disability: thinking and acting globally'[46] highlights the lack of global health focus on the challenges that impaired peoples face from a multiplicity of phenomena including: war and civil strife, nuclear testing, the growth of the arms trade, the export of pollution to 'pollution havens' and the emergence of sweatshops.

Poleykett also pointed out that research methodology is often accused of being dominated by western perspectives of looking at the individual in isolation from other elements such as mind, spirit or nature, which in turn distorts the outcome of the research as well as research being dictated by funders objectives which may not have a direct public health benefit.[47] Scholars attending the SOAS decolonising event[27] drew attention to global geographic disparities in knowledge production as seen in Pan et al's global map within their publication 'World citation and collaboration networks: uncovering the role of geography in science' where by authors from the global south are grossly underrepresented.[48] Consequently, funders of global health research should have the cultural competence and decolonising knowledge to deal with this complex area, which is fraught with power imbalances inherent between research centres of the global north and global south. Imperial College London is leading the way in examining these biases in their educational development unit as seen by their work described on the website 'Examining geographic bias in our curricula'. [49]

\section{Ecology and public health}

The terminology around ecology and human health is developing and is discussed in Buse et al's paper on 'Public health guide to field developments linking ecosystems, environments and health in the Anthropocene'. The Anthropocene is defined as the new geological epoch of humanity's own 
making based on evidence of damaging human influence on the biosphere. This paper describes seven emerging fields, which are: occupational and environmental health; political ecology of health; environmental justice; ecohealth; One Health; ecological public health; and planetary health.[50] Planetary heath[51] is the most recent development in this area, and it is significant that the Lancet has a standalone journal dedicated to the topic titled the 'Lancet Planetary Health'. This shines the light of importance on the public events such as the UCL 'Flourishing Diversity Series' (mentioned earlier) in which displaced indigenous ideas were re-centred and foregrounded to highlight the importance of human health within planetary ecology.

Rebekah Jaung in her article on how decolonising health could save the planet says:

"Indigenous people have always had ecological perspectives on health, which have only recently entered 'mainstream' health discourse. The scope now is planetary health approaches which benefit all people and the natural environment. Ideas we have learned from indigenous people include seeing climate breakdown as a symptom of non-reciprocal and exploitative relationships with land and acknowledging that such a relationship exists. Ways of honouring the land will not only restore it, it will lead to good health for the people who live on it. This is not just a nice sentiment but the approach on which cutting edge thinking on global climate action is structured."[52]

Presently there is a social tide of interest in climate change and health as popularised by the extinction protests seen in major cities and activists such as Greta Thunberg. These issues are likely to challenge the present and future generations of doctors. It is therefore important to incorporate non-biased critical thinking about these issues on global health and ecological public health and raise awareness of the emerging field of planetary health within the medical education curriculum.[53]

\section{Cultural appropriation}

Cultural appropriation occurs when members of one culture (often a historically dominant culture) adopts or misappropriates elements of another culture (often a historically disadvantaged culture). In the context of health, some biomedical therapeutic discoveries have an indigenous knowledge bases.[54], [55] Maridass \& De Britto in 'Origins of Plant Derived Medicines'[54], say that the discovery of some new medicines are credited to traditional approaches which in some cases were based on "trial and error over many years in different cultures and systems of medicine". They go on to say that natural products have been the source of many drugs such as quinine, morphine, paclitaxel camptothecin, etoposide, mevastatin, and artemisinin.[54] Similar accusations of cultural appropriation are also seen in respect of meditation, acupuncture, yoga and other indigenous modalities of treatment which are used and re-branded in the west.[56], [57] The fact that this information is not conveyed in medical education exemplifies an aspect of medical cultural appropriation, which involves indigenous cultural knowledge not being acknowledged and respected by a historically dominant group.

\section{Intersectionality}

Intersectionality[58], [59] is used to describe the multiple 'interlocking' or 'simultaneous' oppressions of race, class, gender, sexuality and disability. It was originally coined by Kimberlé Crenshaw, a feminist, in describing the experiences of women of colour. Social activism has highlighted the health inequalities and higher mortality rates for black women who are disadvantaged by their race and their gender. These health disparities are noted in both the UK and the USA in routine national data sets[60]-[63]. Indeed, a new report from MBRRACE-UK states that "it is striking... we seem to be making little impact. Research is urgently needed to understand 
why black women are five times more likely and Asian women twice as likely to die compared to white women"[63].

We recommend that the curriculum should utilise the term 'intersectionality' as part of the social determinants of health, in order to teach cultural competency, in a way that integrates self, social and global awareness as demonstrated at Columbia University, USA, and described by Cushman et al.[64] They recognised the association between the power and privilege with intersectional identities, which often go unrecognised and unacknowledged by the individuals and groups that hold them and ultimately can affect professional behaviours towards patients and the public. Also using the voices of marginalised individuals or groups who explain their intersectional experiences within teaching sessions would fit in with the concept of social accountability as defined by the World Health Organisation's report that there is an "obligation for medical schools to direct their education, research and service activities towards addressing the priority health concerns of the community, region and/or nation they have a mandate to serve"[65]. In this way marginalised groups experiencing simultaneous oppressions can act as patient educators and become future changemakers finding decolonising solutions for this aspect of inequality.[66], [67]

\section{Decolonising symptoms, signs and investigations}

Decolonising diagnosis of disease requires an awareness of studies that have shown ethnic differences in routine chemistry, fertility, endocrine, cancer, and haematological markers, as well as in vitamins and carotenoids, in children, adolescents and adults. This variation in markers is extensively discussed by Tahmasebi et al in 'Influence of ethnicity on population reference values for biochemical markers' which has a useful Table on the available literature evidence for ethnic differences in biomarker levels.[68] It follows that if white European biochemical normal values are used by laboratories and clinicians with diverse populations, then BAME populations are likely to be placed at an increased risk of misdiagnosis. This in turn results in BAME patients being either treated for conditions they don't have or not receiving the treatment in a timely manner and therefore affect their ability to heal. For instance, if medical students and doctors are not trained in skin diagnosis in darker skin tones, then delays in diagnosis or misdiagnosis in detecting conditions such as skin cancer[69] or cyanosis become more likely. Indeed, the lack of teaching on the appearance of cyanosis in darker skin tones in global north medical schools could feasibly contribute to a BAME patient intersectional excess of mortality.

\section{Decolonising reflective practice}

In the UK, the Academy of Medical Royal Colleges and COPMeD define reflective practice as "the process whereby an individual thinks analytically about anything relating to their professional practice with the intention of gaining insight and using the lessons learned to maintain good practice or make improvements where possible".[70] However, we suggest that it would be prudent to incorporate the concept of 'cultural safety' which arose originally as a decolonising nursing concept from New Zealand to address power imbalances between healthcare practitioners and indigenous New Zealanders. The process of cultural safety would essentially entail that a nurse, doctor or student, as part their reflective practice prior to a patient encounter, quickly checking (reflect) on their privilege status and any potential power imbalances between themselves and the patient. This quick reflection should give insight and situational awareness, aspiring to create a fairer clinical encounter.[71] Cultural safety could also be incorporated into human factors training to improve patient safety. Human Factors training is defined as "Enhancing clinical performance through an understanding of the effects of teamwork, tasks, equipment, workspace, culture and organisation on human behaviour and abilities and application of that 
knowledge in clinical settings".[72]-[74] This type of reflective practice could be developed within the medical reflective practice syllabus as a healthcare human rights checklist, thus improving professionalism[75].

\section{Conclusion}

Our article demonstrates that there is guidance from professional regulatory bodies to improve equality, diversity and inclusion as well as legal imperatives to improve person centred care which links to our recommendation that it is important for healthcare educators, health professionals, and researchers/funders to adopt a 'decolonising attitude' and consider the areas that are highlighted in this paper. A system of education that encourages doctors to recognise and challenge their own implicit biases and cultivate an attitude of open-minded professionalism, is vital to address the complex power imbalances of the legacy of colonisation within health care. Decolonisation includes the tolerance of medical pluralism. We can learn from patients as educators and through public engagement with active listening. We can acknowledge the emerging field of planetary health, which stretches healthcare beyond the individual, public health and global health, and which indigenous peoples have proposed regarding living harmoniously with the planet, pre-colonisation. This is pertinent in light of the growing phenomenon of human migration as consequence of a number of factors including economic opportunities, economic crisis, conflict, and natural disasters stemming from climate change.

\section{Bibliography}

[1] University College London, "Why is my curriculum white?," UCL - Dismantling the Master's House., 2015. [Online]. Available: http://www.dtmh.ucl.ac.uk/videos/curriculum-white/. [Accessed: 26Feb-2019]

[2] P. Gopal, "Yes, we must decolonise: our teaching has to go beyond elite white men," The Guardian, 2017 [Online]. Available: https://www.theguardian.com/commentisfree/2017/oct/27/decoloniseelite-white-men-decolonising-cambridge-university-english-curriculum-literature. [Accessed: 17Mar-2019]

[3] M. Sabaratnam, "Decolonising the curriculum: what's all the fuss about?," School of African Studies University of London, 2017. [Online]. Available: https://www.soas.ac.uk/blogs/study/decolonisingcurriculum-whats-the-fuss/. [Accessed: 17-Mar-2019]

[4] S. B. Stone, S. S. Myers, and C. D. Golden, "Cross-cutting principles for planetary health education," The Lancet Planetary Health, vol. 2, no. 5. Elsevier B.V., pp. e192-e193, 01-May-2018.

[5] L. Porter, "Decolonising the Hidden Medical Curriculum, Some historical perspectives," in Decolonising Decolonising the Hidden Medical Curriculum, 2018 [Online]. Available: https://www.youtube.com/watch?v=8LYGseUrjuA\&list=PLEDbLg0JnsgywL8CgBsMhTTkbY5UP-BTD. [Accessed: 23-Apr-2019]

[6] D. L. Brown, "A surgeon experimented on slave women without anesthesia. Now his statues are under attack," The Washington Post, $2017 . \quad$ [Online]. Available: https://www.washingtonpost.com/news/retropolis/wp/2017/08/29/a-surgeon-experimented-onslave-women-without-anesthesia-now-his-statues-are-underattack/?noredirect=on\&utm_term=.9ff0810905c2. [Accessed: 28-Feb-2019]

[7] "U.S. Public Health Service Syphilis Study at Tuskegee," Centers for Disease Conrol and Prevention. [Online]. Available: https://www.cdc.gov/tuskegee/timeline.htm. [Accessed: 28-Feb-2019]

[8] Equality Challenge Unit, "Unconscious bias in higher education: literature review," 2013. [Online]. Available: https://www.ecu.ac.uk/publications/unconscious-bias-in-higher-education/. [Accessed: 
[9] L. Horvat, D. Horey, P. Romios, and J. Kis-Rigo, "Cultural competence education for health professionals," Cochrane Database Syst. Rev., no. 5, May 2014.

[10] C. Foronda, D.-L. Baptiste, M. M. Reinholdt, and K. Ousman, "Cultural Humility," J. Transcult. Nurs., vol. 27, no. 3, pp. 210-217, May 2016.

[11] F. Gishen and A. Lokugamage, "Diversifying and decolonising the medical curriculum - The BMJ," Blogs BMJ, 2018. [Online]. Available: https://blogs.bmj.com/bmj/2018/10/18/diversifying-anddecolonising-the-medical-curriculum/. [Accessed: 27-Oct-2018]

[12] R. DiAngelo, White Fragility : Why it's so hard for white people to talk about racism. Penguin Books, 2019.

[13] General Medical Council, "GMC publishes its strategy on equality and fairness," General Medical Council, 2018. [Online]. Available: https://www.gmc-uk.org/news/news-archive/gmc-publishes-itsstrategy-on-equality-and-fairness. [Accessed: 17-Mar-2019]

[14] General Medical Council, “Outcomes for graduates 2018," 2018 [Online]. Available: https://www.gmc-uk.org/-/media/documents/dc11326-outcomes-for-graduates-2018_pdf75040796.pdf. [Accessed: 26-Feb-2019]

[15] Council of Europe, "European Convention on Human Rights," Strasbourg, 1950 [Online]. Available: www.conventions.coe.int. [Accessed: 28-Feb-2019]

[16] Council for Europe, "Guide to article 9 freedom of thought, conscience and religion," 2018 [Online]. Available: www.echr.coe.int. [Accessed: 27-Feb-2019]

[17] European Court of Human Rights, Jehovah's Witnesses of Moscow v. Russia, vol. Applicatio. 2010 [Online]. Available: http://hudoc.echr.coe.int/eng?i=001-99221

[18] United Kingdom Supreme Court, Montgomery v Lanarkshire Health Board, vol. [2015] UKS. [Online]. Available: https://www.supremecourt.uk/cases/docs/uksc-2013-0136-judgment.pdf

[19] S. Pathberiya, Patient autonomy and decision making, BMJ 2016;3. London: BMJ, 2016 [Online]. Available: http://www.bmj.com/lookup/doi/10.1136/bmj.i2452. [Accessed: 28-Feb-2019]

[20] UCL Medical School, "Liberating the Curriculum at UCL Medical School," UCL. [Online]. Available: https://wordpress.com/view/liberatingthecurriculumblog.wordpress.com. [Accessed: 23-Apr2019]

[21] University College London, "Decolonising the Medical Curriculum," UCL, 2019. [Online]. Available: https://decolonisingthemedicalcurriculum.wordpress.com/. [Accessed: 17-Mar-2019]

[22] "Decolonising Health," Wellcome Collection. [Online]. Available: https://wellcomecollection.org/events/Wn3LzSoAACsAlcv4. [Accessed: 29-Jul-2018]

[23] "Ayurvedic Man: encounters with Indian medicine upcoming exhibition at Wellcome Collection," Wellcome Collection, 2017. .

[24] UCL Anthropology, "Flourishing Diversity Series," 2019 [Online]. Available: https://www.ucl.ac.uk/anthropology/events/2019/sep/flourishing-diversity-series

[25] BBC World Service;, "Indigenous communities talk climate change," BBC World Service, UK, 2019 [Online]. Available: https://www.bbc.co.uk/programmes/w172wx8tbxr597b

[26] S. Pyãnko, Benki ; Haynes, "A Brazilian Indigenous Leader Shares His Climate Solutions," TIME Mag., 2019 [Online]. Available: https://time.com/5676877/indigenous-leader-amazon-brazil/

[27] SOAS, "Applying a Decolonial Lens to Research Development Practices," 2019 [Online]. Available: https://www.soas.ac.uk/blogs/study/applying-a-decolonial-lens-to-research-developmentpractices/ 
[28] "Page 148: one man in traditional religious clothing (identified as Maharaja Ranjit Singh), the other in European dress [Image]." [Online]. Available: https://wellcomecollection.org/works/vwr3kfku?page=2\&query=indian man in traditional dress. [Accessed: 27-Apr-2019]

[29] A. Quijano, "Coloniality And Modernity/Rationality," Cult. Stud., vol. 21, no. 2-3, pp. 168-178, Mar. 2007.

[30] J. M. Wright, "Practice guidelines by specialist societies are surprisingly deficient.," Int. J. Clin. Pract., vol. 61, no. 7, pp. 1076-7, Jul. 2007.

[31] D. H. Lee and O. Vielemeyer, "Analysis of Overall Level of Evidence Behind Infectious Diseases Society of America Practice Guidelines," Arch. Intern. Med., 2011.

[32] K. Prusova, L. Churcher, A. Tyler, and A. U. Lokugamage, "Royal College of Obstetricians and Gynaecologists guidelines: how evidence-based are they?," J. Obstet. Gynaecol., vol. 34, no. 8, pp. 706-11, Nov. 2014.

[33] R. Ghui, J. K. Bansal, C. McLaughlin, A. Kotaska, and A. Lokugamage, "An evaluation of the guidelines of the Society of Obstetricians and Gynaecologists of Canada," J. Obstet. Gynaecol. (Lahore)., vol. 36, no. 5, pp. 658-662, Jul. 2016.

[34] C. Charles, A. Gafni, and E. Freeman, "The evidence-based medicine model of clinical practice: scientific teaching or belief-based preaching?," J. Eval. Clin. Pract., vol. 17, no. 4, pp. 597-605, Aug. 2011.

[35] K. J. Coleman et al., "Racial-Ethnic Differences in Psychiatric Diagnoses and Treatment Across 11 Health Care Systems in the Mental Health Research Network.," Psychiatr. Serv., vol. 67, no. 7, pp. 749-57, 2016.

[36] N. Y. Chavez-Dueñas, H. Y. Adames, J. G. Perez-Chavez, and S. P. Salas, "Healing ethno-racial trauma in Latinx immigrant communities: Cultivating hope, resistance, and action.," Am. Psychol., vol. 74, no. 1, pp. 49-62, Jan. 2019.

[37] J. Fay, "Decolonising mental health services one prejudice at a time: psychological, sociological, ecological, and cultural considerations," Settl. Colon. Stud., vol. 8, no. 1, pp. 47-59, Jan. 2018 [Online]. Available: https://www.tandfonline.com/doi/full/10.1080/2201473X.2016.1199828. [Accessed: 29-Jul-2018]

[38] S. Davis, "Being a Queer and/or Trans Person of Colour in the UK: Psychology, Intersectionality and Subjectivity," University of Brighton, 2017 [Online]. Available: https://core.ac.uk/download/pdf/131100157.pdf. [Accessed: 29-Jul-2018]

[39] R. Linklater, Decolonizing trauma work: indigenous stories and strategies. [Online]. Available: https://fernwoodpublishing.ca/book/decolonizing-trauma-work. [Accessed: 29-Jul-2018]

[40] State of Hawaii, A Bill for an Act relating to the Composition of the State Council on Mental Health. State of Hawaii, 2019 [Online]. Available: https://www.capitol.hawaii.gov/session2019/bills/HB292_.pdf. [Accessed: 12-Mar-2019]

[41] The Office of Hawaiian Affairs, "OHA-4 Addressing Native Hawaiian Mental Health Needs Through Culturally Informed Programs and Services," 2018 [Online]. Available: http://www.ksbe.edu/_assets/spi/hulili/hulili_vol_7/7_Hulili_2011_Vol7_Carlton_et_al.pdf;

[Accessed: 12-Mar-2019]

[42] C. C. Nadelson and C. A. Bernstein, "Decolonising the Body: Restoring Sacred Vitality," Atl. Crit. Stud. Gender, Cult. Soc. Justice, vol. 29, no. 2, 2005.

[43] N. A. Youssef, L. Lockwood, S. Su, G. Hao, and B. P. F. Rutten, "The Effects of Trauma, with or without PTSD, on the Transgenerational DNA Methylation Alterations in Human Offsprings.," Brain Sci., vol. 8, no. 5, May 2018. 
[44] N. Benachar, "Culture in the clinical encounter," Decolonising the Medical Curriculum, UCL Medical School, 2018. [Online]. Available: https://decolonisingthemedicalcurriculum.wordpress.com/sixaspects-of-decolonising/decolonising-professional-behaviour/culture-in-the-clinical-encounter/.

[Accessed: 25-Apr-2019]

[45] R. Smith, "Moving from global heath 3.0 to global health 4.0," The BMJ Opinion, 2013. [Online]. Available: https://blogs.bmj.com/bmj/2013/10/08/richard-smith-moving-from-global-heath-3-0to-global-health-4-0/

[46] H. Meekosha, "Decolonising disability: Thinking and acting globally," Disabil. Soc., vol. 26, no. 6, pp. 667-682, Oct. 2011.

[47] Centre for Education Studies, "What is decolonising methodology?," University of Warwick, Coventry, $2018.2 \quad$ [Online]. Available: https://warwick.ac.uk/fac/soc/ces/research/current/socialtheory/maps/decolonising/

[48] R. K. Pan, K. Kaski, and S. Fortunato, "World citation and collaboration networks: Uncovering the role of geography in science," Sci. Rep., vol. 2, 2012.

[49] Imperial College London, "Examining geographic bias in our curricula." [Online]. Available: https://www.imperial.ac.uk/staff/educational-development/workshops/focus-on/geographicbias/. [Accessed: 15-Nov-2019]

[50] C. G. Buse et al., "Public health guide to field developments linking ecosystems, environments and health in the Anthropocene," J. Epidemiol. Community Health, vol. 72, no. 5, pp. 420-425, 2018.

[51] R. Horton and S. Lo, "Planetary health: A new science for exceptional action," The Lancet, vol. 386, no. 10007. Lancet Publishing Group, pp. 1921-1922, 14-Nov-2015.

[52] R. Jones, "Climate change and Indigenous Health Promotion," Glob. Health Promot., vol. 26, no. 3_suppl, pp. 73-81, Apr. 2019.

[53] T. Asakura, H. Mallee, S. Tomokawa, K. Moji, and J. Kobayashi, "The ecosystem approach to health is a promising strategy in international development: Lessons from Japan and Laos," Global. Health, vol. 11, no. 1, Feb. 2015.

[54] M. Maridass and A. J. De Britto, "Origins of Plant Derived Medicines," 2008 [Online]. Available: https://opensiuc.lib.siu.edu/ebl/vol2008/iss1/44/. [Accessed: 18-Mar-2019]

[55] A. W. Jones, "Early drug discovery and the rise of pharmaceutical chemistry," Drug Test. Anal., vol. 3, no. 6, pp. 337-344, Jun. 2011.

[56] S. Gandhi and L. Wolff, "Yoga and the Roots of Cultural Appropriation," Praxis Center, Arcus Center for Social Justice Leadership Kalamazoo College, 2017. [Online]. Available: https://www.kzoo.edu/praxis/yoga/

[57] K. A. Surmitis, J. Fox, and D. Gutierrez, "Meditation and Appropriation: Best Practices for Counselors Who Utilize Meditation," Couns. Values, vol. 63, no. 1, pp. 4-16, Apr. 2018.

[58] J. C. Nash, "Re-thinking intersectionality," Fem. Rev., vol. 89, no. 1, pp. 1-15, Jun. 2008.

[59] Colombia Law School, "Kimberlé Crenshaw on Intersectionality, More than Two Decades Later," 2017. [Online]. Available: https://www.law.columbia.edu/pt-br/news/2017/06/kimberlecrenshaw-intersectionality. [Accessed: 27-Apr-2019]

[60] N. Krieger, J. T. Chen, B. A. Coull, J. Beckfield, M. V Kiang, and P. D. Waterman, "Jim Crow and premature mortality among the US Black and White population, 1960-2009: an age-period-cohort analysis.," Epidemiology, vol. 25, no. 4, pp. 494-504, Jul. 2014.

[61] A. M. McCarthy, J. Yang, and K. Armstrong, "Increasing disparities in breast cancer mortality from 1979 to 2010 for US black women aged 20 to 49 years.," Am. J. Public Health, vol. 105 Suppl, no. S3, pp. S446-8, Jul. 2015. 
[62] M. Nair, M. Knight, and J. Kurinczuk, "Risk factors and newborn outcomes associated with maternal deaths in the UK from 2009 to 2013: a national case-control study," BJOG An Int. J. Obstet. Gynaecol., vol. 123, no. 10, pp. 1654-1662, Sep. 2016.

[63] M. Knight et al., "Saving Lives, Improving Mothers' Care - Lessons learned to inform maternity care from the UK and Ireland Confidential Enquiries into Maternal Deaths and Morbidity 2014-16.," Oxford, 2018.

[64] L. F. Cushman et al., "Cultural competency training for public health students: integrating self, social, and global awareness into a master of public health curriculum.," Am. J. Public Health, vol. 105 Suppl 1, pp. S132-40, Mar. 2015 [Online]. Available: http://www.ncbi.nlm.nih.gov/pubmed/25706008. [Accessed: 19-Nov-2019]

[65] C. Beolen and J. E. Heck, "Defining and measuring the social accountability of medical schools," Geneva, 1995 [Online]. Available: https://apps.who.int/iris/handle/10665/59441. [Accessed: 26Feb-2019]

[66] A. U. Lokugamage, "A 'Footprints' approach to patient experience and organisational development - The BMJ," BMJ Opinion, 2017. [Online]. Available: https://blogs.bmj.com/bmj/2017/01/26/afootprints-approach-to-patient-experience-and-organisational-development/. [Accessed: 19-Nov2019]

[67] A. Towle et al., "Active patient involvement in the education of health professionals," Medical Education, vol. 44, no. 1. pp. 64-74, Jan-2010.

[68] H. Tahmasebi, K. Trajcevski, V. Higgins, and K. Adeli, "Influence of ethnicity on population reference values for biochemical markers," Crit. Rev. Clin. Lab. Sci., vol. 55, no. 5, pp. 359-375, Jul. 2018.

[69] S. Hu, "Skin Cancer in Ethnic Minorities," Cutan. Oncol. TODAY, vol. December, pp. 5-8, 2011.

[70] Academy of Medical Royal Colleges, Conference of Postgraduate Medical Deans of the United Kingdom, General Medical Council, and Medical Schools Council, "Academy and COPMeD Reflective Practice Toolkit," 2018 [Online]. Available: http://www.aomrc.org.uk/wpcontent/uploads/2018/08/Reflective_Practice_Toolkit_AoMRC_CoPMED_0818.pdf. [Accessed: 15Nov-2019]

[71] S. Richardson and T. Williams, "Why is cultural safety essential in health care?," Med. Law, vol. 26, no. 4, pp. 699-707, Dec. 2007.

[72] Department of Health, "Department of Health Human Factors Reference Group - Interim Report, 1 March 2012" [Online]. Available: https://www.england.nhs.uk/wp-content/uploads/2013/11/DHrep.pdf. [Accessed: 15-Nov-2019]

[73] Care Quality Commission, Department of Health, and Health Education England, "Human Factors in Healthcare, A Concordat from the National Quality Board," 2013 [Online]. Available: https://www.england.nhs.uk/wp-content/uploads/2013/11/nqb-hum-fact-concord.pdf. [Accessed: 15-Nov-2019]

[74] K. Catchpole and P. McCulloch, "Human factors in critical care: towards standardized integrated human-centred systems of work," Curr. Opin. Crit. Care, vol. 16, no. 6, pp. 618-622, Dec. 2010 [Online]. Available: https://insights.ovid.com/crossref?an=00075198-201012000-00018. [Accessed: 15-Nov-2019]

[75] A. Lokugamage, "Maternal mortality-undoing systemic biases and privileges - The BMJ," BMJ Opin., 2019 [Online]. Available: https://blogs.bmj.com/bmj/2019/04/08/amali-lokugamage-maternalmortality-undoing-systemic-biases-and-privileges/. [Accessed: 23-Apr-2019] 